\title{
PEDAGOGIA DO ESPORTE E PROJETOS SOCIAIS: INTERLOCUÇÕES SOBRE A PRÁTICA PEDAGÓGICA
}

\author{
PEDAGOGY OF SPORT AND SOCIAL PROJECTS: DIALOGUES ABOUT \\ EDUCATIONAL PRACTICE
}

\begin{abstract}
PEDAGOGÍA DEL DEPORTE Y PROYECTOS SOCIALES: DIÁLOGOS SOBRE LA PRÁCTICA DOCENTE
\end{abstract}

\author{
Gisele Viola Machado*, Larissa Rafaela Galatti*, Roberto Rodrigues Paes*
}

Palavras-chave Política social.

Esportes.

Aprendizagem.

Educação.
Resumo: 0 estudo conferiu, em um projeto social, o tratamento educacional dado ao esporte, verificando as finalidades de ensino e os conteúdos ensinados pelos professores e a percepção dos alunos quanto aos mesmos. Os procedimentos metodológicos adotados foram entrevista semiestruturada com dez professores e entrevista com 45 alunos participantes do Programa (média de 12,5 anos), a partir da técnica de focus group. Os resultados evidenciam avanços no trato educacional com 0 esporte, mas denunciam a persistência de incongruência entre finalidades e conteúdos dos professores e maior relação entre conteúdos aplicados e aprendizagem dos alunos.

Keywords:

Public policy. Sports. Learning. Education.

Abstract: The study focused on the educational treatment of sport in a social project, examining teaching purposes and contents proposed and students' perspectives about them. The methodological procedures were semi-structured interviews with 10 teachers and interviews with 45 students in the program (mean 12.5 years of age), using focus groups. The results show improvements in the educational approach to sport, but indicate a continuing mismatch between teachers' aims and contents, as well as better relations between contents applied and students' learning.

Resumen: Esta investigación examinó, en un proyecto social de un ayuntamiento, el tratamiento educacional dado al deporte, analizando las finalidades de la enseñanza y los contenidos impartidos por los profesores, además de la percepción de los alumnos en cuanto a los mismos. Los procedimientos metodológicos adoptados fueron una entrevista semiestructurada con diez profesores y entrevista con 45 alumnos que participan del Programa (promedio de 12,5 años) a partir de la técnica de grupo focal. Los resultados muestran avances en el trato educacional con el deporte, pero denuncian la persistencia de incongruencia entre finalidades y contenidos de los profesores y mayor relación entre contenidos aplicados y aprendizaje de los alumnos.
*Universidade Estadual de Campinas (UNICAMP). Campinas, SP, Brasil. Email: giseleviola_ef@yahoo.com.br Recebido em: 30-06-2014 Aprovado em: 21-01-2015 (c) (i) () Licence 


\section{INTRODUÇÃO}

Nas últimas três décadas o esporte tem assumido novos significados, reafirmando seu status de fenômeno sociocultural, sendo parte da vida das pessoas e elemento integrador no tecido social, contribuindo para recuperação e fortalecimento de identidades nacionais na nova configuração geográfica mundial. E, com sua ascensão nos meios de comunicação, em especial em sua faceta profissional, vem assumindo um papel de extrema relevância na economia mundial.

Coakley (1998) afirma que o fenômeno vive seu auge na história do homem, tendo importante influência em sua vida, estando intimamente relacionado com a construção do caráter, saúde e patriotismo. Diante da pluralidade do fenômeno, Galatti (2010) busca sintetizar (embora não esgotar) os múltiplos significados do esporte contemporâneo, organizando-os em sete grupos que podem se relacionar e coincidir: educação, socialização, lazer, profissão, representação, saúde e estética.

Dentre tantas possibilidades, neste estudo enfocamos o esporte em seu significado educacional, altamente relacionado ao de socialização - destacando que esses são os significados que permeiam os demais, uma vez que a busca de redes de relacionamento e de integração social está presente em qualquer significado que se dê à prática esportiva.

Também consideramos sempre haver um componente educacional (seja positivo ou negativo) nas práticas esportivas, dado que o esporte pressupõe a troca de informação e 0 relacionamento interpessoal, constituindo espaço de constantes processos de educação e coeducação, formal, não formal ou informal. Gutierrez Sanmartín (2003) destaca as possíveis contribuições do esporte no aspecto educacional, quanto a modos de comportamento em grupo e individuais.

A partir do exposto, a relevância e importância das práticas esportivas vão além da revelação de atletas. Trata-se da inserção na cultura esportiva, da possibilidade de conhecer o esporte, desfrutar de sua prática e, a partir de um adequado processo de ensino, vivência, aprendizagem e treinamento, manter-se no ambiente esportivo em diferentes papéis - atleta, espectador, torcedor, dirigente, árbitro, investidor etc. - nos múltiplos cenários possíveis. Para tal, não basta apenas uma boa planificação de aulas e treinamentos; é necessário ampliar o conteúdo proposto na prática esportiva, valorizando o esporte e estimulando valores e modos de comportamento.

Para tal, os conteúdos abordados - além de terem significado aos alunos - precisam ultrapassar a esfera da prática motora, sendo parte de um processo de ensino, vivência e aprendizagem que privilegie o ensino de valores e comportamentos, questões históricas e culturais sobre o esporte e as modalidades aprendidas, a discussão sobre a ética no esporte, a influência da mídia, o respeito, entre outros conhecimentos que fazem parte do universo esportivo e contribuem para o aspecto educacional e social da prática esportiva.

Devemos ressaltar que em instituições de ensino formal - escolas, universidades - e não formal - clubes, prefeituras e projetos sociais - o trabalho com o esporte deve ser organizado e sistematizado a partir de objetivos educacionais intencionalmente estruturados, visando o pleno desenvolvimento dos participantes.

Dentre as diferentes maneiras de organizar os conteúdos estudados junto aos alunos daremos ênfase, nesse artigo, aos procedimentos adotados a partir de três referenciais da 
Pedagogia do Esporte (PE): o técnico-tático (questões motoras, físicas, fundamentos e sistemas de cada modalidade), o socioeducativo (valores e modos de comportamento) e histórico-culturais (regras, histórias sobre o esporte e as modalidades esportivas), como indicam os autores: Paes (1996), Galatti (2006), Galatti et al. (2008), Paes e Balbino (2009), Galatti, Darido e Paes (2010), Machado, Galatti e Paes (2011), Machado (2012) e Machado, Galatti e Paes (2014).

O referencial técnico-tático diz respeito à organização e sistematização pedagógica das modalidades esportivas para a vivência e prática das mesmas, além da escolha metodológica para sua aplicação. Já o socioeducativo trata de valores e modos de comportamento que podem ser estimulados se intencionalmente organizados e sistematizados como conteúdo esportivo. Por sua vez, o referencial histórico-cultural visa fortalecer o trato pedagógico com os conteúdos esportivos na medida em que busca tratar dos conhecimentos que caracterizam o esporte como um elemento cultural e social. $O$ quadro 1 sintetiza os três referenciais da PE que balizam esse estudo:

Quadro 1 - Síntese dos referenciais da PE

\begin{tabular}{|c|c|c|}
\hline \multicolumn{3}{|c|}{ REFERENCIAIS } \\
\hline \multicolumn{3}{|c|}{$\begin{array}{l}\text { Métodos de ensino e aprendizagem; } \\
\text { Planejamento ao longo do período (mês, bimestre, semestre, ano...); } \\
\text { Organização de cada aula/treino; } \\
\text { Adequação da proposta ao grupo de trabalho; }\end{array}$} \\
\hline TÉCNICO-TÁTICO & SOCIOEDUCATIVO & HISTÓRICO-CULTURAL \\
\hline $\begin{array}{l}\text { Estratégias } \\
\text { Aspectos Táticos Ofensivos, } \\
\text { Defensivos e de Transição, } \\
\text { Habilidades Motoras Gerais } \\
\text { Fundamentos Especializados, } \\
\text { Capacidades biomotoras }\end{array}$ & $\begin{array}{l}\text { Promover a discussão de } \\
\text { princípios, valores e modos de } \\
\text { comportamento; } \\
\text { Propor a troca de papéis (colocar- } \\
\text { se no lugar do outro); } \\
\text { Promover a participação, inclusão, } \\
\text { diversificação, a coeducação e a } \\
\text { autonomia; } \\
\text { Construir um ambiente favorável } \\
\text { para desenvolvimento de relações } \\
\text { intrapessoais e interpessoais } \\
\text { (coletivas); } \\
\text { Estabelecer relações entre o que } \\
\text { acontece na aula de esportes com } \\
\text { a vida em comunidade. }\end{array}$ & $\begin{array}{l}\text { História das modalidades } \\
\text { esportivas; } \\
\text { Evolução das modalidades; } \\
\text { Regras e contexto de suas } \\
\text { alterações; } \\
\text { Principais competições em } \\
\text { nível local, regional, nacional e } \\
\text { internacional; } \\
\text { Personalidades de cada } \\
\text { modalidade; } \\
\text { Outros saberes necessários para a } \\
\text { compreensão da modalidade. }\end{array}$ \\
\hline
\end{tabular}

Fonte: Adaptado de partes das obras: Galatti, Darido e Paes (2010), Machado (2012) e Machado, Galatti e Paes (2014)

Neste sentido que este estudo torna-se relevante, pois buscou identificar em uma instituição de ensino não formal no município de Taubaté, no Programa Ensino Esporte e Juventude (PEEJ), como tem sido o tratamento pedagógico com o fenômeno esporte a partir da perspectiva dos professores e dos alunos do programa.

\section{MATERIAIS E MÉTODOS}

O estudo inicialmente partiu de uma revisão de literatura acerca da Pedagogia do Esporte e projetos sociais e caminhou para uma pesquisa de campo realizada no Programa Ensino Esporte e Juventude (PEEJ), um programa socioeducativo mantido pelo poder público 
municipal que existe desde 2001, atendendo em 2012 cerca de 2000 crianças e adolescentes de sete a quinze anos, no município de Taubaté-SP, em cinco unidades em diferentes bairros periféricos, no contraturno escolar, oferecendo atividades que visam o desenvolvimento social, cultural, afetivo e físico-motor dos participantes (PROGRAMA ENSINO ESPORTE E JUVENTUDE, 2008).

$O$ projeto esportivo do PEEJ apresenta seis finalidades, sendo: (a) Vivenciar modalidades esportivas; (b) Estimular o desenvolvimento cognitivo, físico-motor e afetivosocial; (c) Ampliar o conhecimento cultural sobre o esporte; (d) Conscientizar sobre a importância da atividade física e hábitos saudáveis e (e) Estimular a autonomia e a reflexão crítica preparando o aluno para o exercício da cidadania (PROGRAMA ENSINO ESPORTE E JUVENTUDE, 2011).

Para tal, tratamos de conhecer como o esporte é abordado no projeto, a partir de uma entrevista com os professores do mesmo. Participaram da pesquisa dez professores, dois de cada unidade, sendo um professor de alunos entre sete e dez anos e o outro de alunos entre 11 e 15 anos selecionados aleatoriamente, de acordo com interesse e disponibilidade em participar da pesquisa.

Segundo Marconi e Lakatos (2010) a entrevista caracteriza-se pelo encontro entre duas pessoas, com a finalidade de uma delas obter respostas sobre um assunto específico, de forma profissional. Pelas diversas formas de entrevistas, optamos pela utilização da entrevista semiestruturada, pois o entrevistador tem liberdade para discorrer cada situação na direção que considere adequada, apresentando-se como uma forma de explorar mais amplamente alguma questão.

A entrevista realizada com os professores foi organizada em dois blocos distintos, sendo eles: (a) Finalidades das aulas esportivas e (b) Conteúdos de ensino.

Posteriormente, foi realizada uma entrevista com 45 alunos entre 11 e 15 anos sobre o que eles aprendem nas aulas esportivas através da técnica do focus group, que se utiliza da cooperação entre os participantes para chegar à conclusão de um assunto a partir de um consenso discursivo (BRITO, 2008).

Devido ao grande número de alunos, eles foram divididos aleatoriamente em cinco grupos de nove alunos cada. Para a coleta dos dados, tanto da entrevista com os professores e com os alunos, utilizamos uma filmadora Sony Dcr-Sr47 colocada em um ponto fixo da sala, facilitando a captação da fala de todos.

Para a análise das entrevistas (tanto com os professores quanto com os alunos) utilizamos o método de Análise de Conteúdo, que, segundo Bardin (2011), tem três fases de análise: (a) Pré-análise: é a organização do material, que tem por finalidade tornar operacionais e sistematizar as primeiras considerações; (b) Exploração do material: é a fase da análise propriamente dita; (c) Tratamento dos resultados: os resultados passam a ser tratados de maneira a torná-los significativos e válidos. Bardin (2011) ainda aponta que os mesmos podem ser tratados quantitativa ou qualitativamente. No caso desta pesquisa, nosso enfoque foi qualitativo, no qual realizamos um debate com os autores da Pedagogia do Esporte.

O projeto foi aprovado pelo Comitê de Ética da Universidade de Taubaté sob o protocolo 489/11 em outubro de 2011. 


\section{A PRÁTICA PEDAGÓGICA NOS PROJETOS SOCIAIS}

Os projetos sociais começaram a surgir no Brasil a partir das primeiras décadas do século XX (ISAYAMA; LINHALES, 2008) e, no século XXI, segundo Machado (2012), configuram-se como uma prática cultural legitimada pela sociedade, pelo Estado e pelo mercado. Desde seu surgimento, passaram por diferentes concepções, e, segundo Zaluar (1994), contribuem para complementar os processos educativos formais (escola), especialmente no que diz respeito às populações em situações de vulnerabilidade social.

Na contemporaneidade, tais projetos surgem com a justificativa de oferecer à população em vulnerabilidade social oportunidade de ocupação do tempo livre, com a finalidade de minimizar a exposição a situações de risco.

Dentre as ações de políticas públicas, cerca de $20 \%$ delas atendem crianças e adolescentes com idades entre sete e 14 anos, para os quais o esporte tem sido um dos conteúdos mais atrativos (MARTINS; MELO, 2003, HIRAMA, 2008).

Diante deste cenário, diversos estudos têm abordado o tema esporte e projetos sociais (DONAHUE; RIP; VALLERAND, 2009; SCHULENKORF, 2010; GIORGIO, 2011; HOLT; NEELY, 2011; GIULIANOTTI, 2012). Todavia, em sua grande parte as discussões são pautadas nas justificativas para sua implantação, nos motivos para participação e no impacto dos seus resultados do desenvolvimento humano. Por conseguinte, faltam estudos que tratem de uma das dimensões fundamentais dos projetos sociais que dá sentido aos objetivos propostos por tais instituições (MACHADO, 2012), os currículos desenvolvidos nesses espaços.

Melo (2004, p. 105) faz uma crítica sobre a associação indiscriminada entre esporte, 0 resgate de cidadania e projetos sociais. Para 0 autor, pela maneira como tais projetos têm sido tratados, "[...] qualquer ação que tire os jovens da rua é resgate de cidadania". Podemos encontrar essa relação em diversos estudos, como o de Cunha (2007), Eiras et al. (2009), Souza et al. (2010), Castro e Souza (2011), porém torna-se essencial uma prática pedagógica organizada e sistematizada para buscar atingir tais objetivos (MACHADO; GALATTI; PAES, 2014).

Embora o espaço da educação não formal possa e deva ser também um local para a promoção da cidadania, tendo em vista que "[...] o processo de formação de sujeitos, de cidadãos é um processo que passa pela escolarização, mas não se esgota nela" (MELO, 2004, p.113), apenas afirmar ou estabelecer como objetivo tal formação não garante que na prática ela aconteça.

A mesma relação pode ser construída com o fenômeno esportivo em projetos sociais. Embora diversos autores da Pedagogia do Esporte afirmem que o esporte detém um papel educacional, também corroboram que apenas seu potencial não garante tal alcance (HIRAMA; JOAQUIM; MONTAGNER, 2011, REVERDITO; SCAGLIA 2009, BENTO, 2006, PAES, 1996). Para esses autores, é fundamental que as aulas sejam organizadas, sistematizadas, aplicadas (metodologia) e avaliadas, de forma a potencializar suas possibilidades educacionais.

Este estudo torna-se fundamental, pois para além de discutir os projetos sociais enquanto espaço com potencial para a formação de crianças e adolescentes e o esporte como facilitador nesse processo, tendo em vista que a literatura já trouxe tais respostas com base em diferentes estudos (ZALUAR, 1994; SHAFFER; WITTES, 2006; CUNHA, 2007; 
DONAHUE; RIP; VALLERAND, 2009; EIRAS et al., 2009; SCHULENKORF, 2010; SOUZA et al., 2010; CASTRO; SOUZA, 2011; GIORGIO, 2011; HOLT; NEELY, 2011; MACHADO; GALATTI; PAES, 2011; GIULIANOTTI, 2012; MACHADO, 2012), buscaremos investigar como os professores têm organizado a prática pedagógica e o que os alunos têm identificado como aprendizagem nas aulas de esporte nos projetos sociais, fazendo uma associação entre ambos.

\section{PESQUISA DE CAMPO: RESULTADOS E DISCUSSÕES}

Participaram da pesquisa dez professores de Educação Física com idade média de 25,7 anos (desvio padrão - d.p. 2,1), atuação no PEEJ como professor de 1,6 anos (d. p. de $1,7)$, sendo formados em média há quatro anos (d.p. 1,7).

Quanto aos alunos, foram entrevistados 45 , que participavam de aulas esportivas no PEEJ em uma das cinco unidades. As aulas tinham duração de 1 h e 30 minutos e eram oferecidas de $3^{\underline{a}}$ a $6^{\underline{a}}$ feira. Os alunos eram separados por turmas conforme a idade, neste caso, a turma 4, com alunos de 11 e 12 anos e a turma 5, com os alunos de 13 a 15 anos.

Dentre o grupo entrevistado tivemos 14 meninas e 31 meninos, correspondendo a $31,1 \%$ e $68,8 \%$, respectivamente.

Em relação à idade, o grupo era relativamente novo, sendo 13 alunos com idade de 11 anos (28,8\%), 11 com idade de 12 anos (24,4\%), 12 alunos com idade de 13 anos (26,6\%), três com idade de 14 anos $(6,6 \%)$ e seis alunos com idade de 15 anos $(13,3 \%)$.

Sobre o tempo de participação no Programa, tivemos uma variação muito significativa, indo desde alunos que haviam entrado duas semanas antes da entrevista e outros que já eram matriculados desde a inauguração da unidade, no ano de 2004, há sete anos.

Dos alunos entrevistados, 40 afirmaram que praticam esporte fora do PEEJ e apenas cinco não praticam, correspondendo a $88,8 \%$ e $11,1 \%$, respectivamente.

Dentre os alunos que praticam esporte fora do PEEJ, 26 afirmaram que o fazem na escola (65\%), dez (25\%) participam de aulas na educação não formal, como clubes e centros de treinamentos, e apenas seis (15\%) disseram que participam de práticas esportivas na rua, ou em casa - educação informal. Ressaltamos que dois alunos apontaram mais de um lugar para a prática esportiva fora do PEEJ.

Inicialmente apresentaremos os resultados obtidos a partir da entrevista com os professores através de um quadro sintético que apresenta a descrição analítica da fala dos mesmos, apresentando as principais ideias. Em seguida trataremos os resultados realizando comparações coletivas inferenciais sobre os mesmos, de acordo com a técnica da análise de conteúdo; posteriormente realizaremos o mesmo processo com os alunos. Por fim, faremos uma discussão buscando cruzar os dados obtidos entre a entrevista dos professores e a dos alunos.

A primeira pergunta realizada foi: "Quais são as finalidades das aulas esportivas no PEEJ"? 
Quadro 2 - Entrevista dos professores sobre as finalidades do esporte nos projetos sociais

\begin{tabular}{|c|c|}
\hline Professor entrevistado & Respostas \\
\hline Professor 1 & $\begin{array}{l}\text { Desenvolvimento motor e conhecimento, contudo, o foco principal seriam os } \\
\text { valores, as virtudes e a formação do cidadão. }\end{array}$ \\
\hline Professor 2 & $\begin{array}{l}\text { O objetivo maior é a conscientização, os valores e as virtudes que auxiliam na } \\
\text { melhora e transformação da sociedade. Para ele, o desenvolvimento motor é uma } \\
\text { consequência nas aulas. }\end{array}$ \\
\hline Professor 3 & $\begin{array}{l}\text { O foco maior está nos valores e nas atitudes, embora haja o trabalho com as } \\
\text { habilidades também, mas o mais importante seriam os valores e as atitudes dos } \\
\text { alunos. }\end{array}$ \\
\hline Professor 4 & $\begin{array}{l}\text { Proporcionar aos alunos um conhecimento prévio sobre as modalidades esportivas } \\
\text { e ensinar sobre as situações que ocorrem no esporte, como a cooperação, a } \\
\text { organização de grupos, os valores de uma forma geral. Além de ser uma forma dos } \\
\text { alunos praticarem atividade física. }\end{array}$ \\
\hline Professor 5 & $\begin{array}{l}\text { Preparar os alunos para terem um conhecimento maior sobre as modalidades } \\
\text { esportivas. }\end{array}$ \\
\hline Professor 6 & $\begin{array}{l}\text { Ampliar o repertório motor dos alunos, desde as habilidades motoras gerais às } \\
\text { específicas de cada modalidade. }\end{array}$ \\
\hline Professor 7 & $\begin{array}{l}\text { O foco está mais nas questões sociais, ensinar através do esporte, sabendo lidar } \\
\text { com as regras dentro e fora das quadras. }\end{array}$ \\
\hline Professor 8 & $\begin{array}{l}\text { Passar valores e virtudes aos alunos para que eles consigam viver bem em } \\
\text { sociedade. }\end{array}$ \\
\hline Professor 9 & $\begin{array}{l}\text { O mais importante é o lado social, integrar os alunos e ensiná-los a respeitar e a } \\
\text { conviver. }\end{array}$ \\
\hline Professor 10 & Ensinar os alunos a entender o esporte. \\
\hline
\end{tabular}

Fonte: Machado (2012, p. 92-93)

De uma forma geral os professores apontam que as aulas esportivas nos projetos sociais contribuem principalmente para a promoção e o desenvolvimento de valores e modos de comportamento, conteúdos que estão presentes no referencial socioeducativo. Quatro professores destacaram como finalidade conhecer ou entender o esporte, o que pode estar associado ao referencial histórico-cultural, dentre os quais o P5 e o P10 citam este referencial exclusivamente. Também foram quatro os professores que citaram o desenvolvimento de habilidades motoras, sendo os professores 1, 2, 3 e 6 , ainda que os três primeiros também destaquem o referencial socioeducativo e 06 o técnico-tático.

Ao relacionarmos as finalidades das aulas esportivas apontadas pelos professores e os objetivos dos projetos sociais que atendem crianças e adolescentes percebemos uma relação positiva entre eles, pois ambos destacam a importância de fomentar o desenvolvimento social dos alunos, destacando o respeito, o trabalho em equipe, a socialização e o convívio em sociedade (ZALUAR, 1994; EIRAS et al., 2009; CASTRO; SOUZA, 2010; MACHADO; GALATTI; PAES, 2011).

A clareza sobre as finalidades das aulas esportivas norteará todas as demais ações pedagógicas do professor, como a seleção e organização dos conteúdos e de procedimentos pedagógicos e o planejamento das aulas. Portanto, se as finalidades descritas pelos professores, em sua maioria, se voltam para o estímulo de valores e modos de comportamento, é fundamental que as aulas apontem para a mesma direção. 
A seguir apresentaremos um quadro sintético categorizado a partir dos referenciais da PE sobre a pergunta dos conteúdos ensinados nas aulas.

Quadro 3 - Conteúdos ensinados pelos professores

\begin{tabular}{|c|c|c|c|}
\hline Professor & Referencial Técnico-tático & Referencial Socioeducativo & $\begin{array}{c}\text { Referencial Histórico- } \\
\text { cultural }\end{array}$ \\
\hline Professor 1 & $\begin{array}{l}\text { Equilíbrio, a manipulação, a } \\
\text { coordenação motora, a parte } \\
\text { de acrobacias. }\end{array}$ & $\begin{array}{l}\text { Atitude, respeito (mútuo, } \\
\text { às regras), honestidade, } \\
\text { paciência. }\end{array}$ & $\begin{array}{l}\text { Histórias de como surgiram, } \\
\text { onde surgiu, como foi } \\
\text { ao longo do tempo se } \\
\text { desenvolvendo. }\end{array}$ \\
\hline Professor 2 & $\begin{array}{l}\text { Desenvolvimento motor; } \\
\text { Habilidades motoras. }\end{array}$ & $\begin{array}{l}\text { A concentração na aula, o } \\
\text { foco. }\end{array}$ & \\
\hline Professor 3 & $\begin{array}{l}\text { Habilidades, coordenação } \\
\text { motora, equilíbrio, } \\
\text { psicomotricidade. }\end{array}$ & & \\
\hline Professor 4 & $\begin{array}{l}\text { Coordenação motora, } \\
\text { vivência esportiva. }\end{array}$ & A atitude. & \\
\hline Professor 5 & $\begin{array}{l}\text { Manipulativos, visão } \\
\text { periférica, visão lateral. }\end{array}$ & $\begin{array}{l}\text { Valores, como ser educado, } \\
\text { como se portar. }\end{array}$ & \\
\hline Professor 6 & O fundamento em si, o jogo. & $\begin{array}{l}\text { Os valores que se adequam } \\
\text { às necessidades da turma. }\end{array}$ & $\begin{array}{l}\text { Histórico, regras, } \\
\text { curiosidades, os atletas. }\end{array}$ \\
\hline Professor 7 & $\begin{array}{l}\text { Os fundamentos principais, } \\
\text { tática, sistema defensivo, 2-1- } \\
2,2-2-1 \text {. Arremesso, passe, } \\
\text { rebote, bandeja. Manejo de } \\
\text { corpo, controle de bola. }\end{array}$ & & \\
\hline Professor 8 & $\begin{array}{l}\text { Iniciação esportiva, } \\
\text { diferentes modalidades. }\end{array}$ & & $\begin{array}{l}\text { Contexto geral das } \\
\text { modalidades esportivas. }\end{array}$ \\
\hline Professor 9 & A técnica. & Atitudinal o tempo todo. & Conceitual. \\
\hline Professor 10 & $\begin{array}{l}\text { O correr, o arremessar, por } \\
\text { que corre daquele jeito, } \\
\text { por que se arremessa, qual } \\
\text { braço pra arremessar. }\end{array}$ & $\begin{array}{l}\text { As atitudes que eles têm que } \\
\text { ter. }\end{array}$ & $\begin{array}{l}\text { A origem das coisas, por que } \\
\text { surgiu, como surgiu. Como é } \\
\text { feito, quais as regras usadas. }\end{array}$ \\
\hline
\end{tabular}

Fonte: Machado (2012, p 104-105)

Apesar de 0 quadro 2 indicar a finalidade predominante do trato com 0 esporte no projeto à questão socioeducativa, o único referencial apresentado como conteúdo de ensino por todos os professores foi justamente o técnico-tático.

Embora a maioria dos professores tenha apontado para conteúdos de ensino pautados em referenciais da $\mathrm{PE}$, alguns deles não deram tanta ênfase às questões de valores e modos de comportamento e outros três sequer apontaram tais conteúdos como presentes em suas aulas, ainda que quando questionados sobre os objetivos dos projetos sociais os três apontaram para a importância das questões sociais.

Percebemos certa incongruência entre as respostas da questão 1 - sobre as finalidades das aulas esportivas em projetos sociais - e a questão 2 - sobre os conteúdos de ensino dos professores -, talvez pela própria dificuldade em entender o que são conteúdos de ensino.

Libâneo (1994, p. 128) define conteúdos como: "[...] o conjunto de conhecimentos, habilidades, hábitos, modos valorativos e atitudinais de atuação social, organizados pedagógica e didaticamente, tendo em vista a assimilação ativa e aplicação pelos alunos em sua vida diária". 
Zabala (1998) define conteúdos como tudo aquilo que se deve aprender para alcançar determinados objetivos, portanto, serão conteúdos todos aqueles que possibilitem o desenvolvimento das capacidades motoras, afetivas, culturais, de relação interpessoal, de inserção social.

Paes e Balbino (2009) defendem que o ensino do esporte não deve se restringir somente às questões motoras, o que reduziria o significado do esporte. No mesmo sentido, Reverdito e Scaglia (2009) apontam para a importância no trato com questões que possibilitem o desenvolvimento do aluno de forma plena. Bento (2006) afirma que devemos olhar o esporte através de sua função de humanização. Portanto, não podemos falar em humanização sem levar em consideração os aspectos que nos tornam humanos, como os sentimentos, os pensamentos e as emoções. Desta maneira, os conteúdos esportivos precisam caminhar em conjunto com esta humanização, o que é destacado por alguns professores que trabalham com valores e modos de comportamento, assim como com o conhecimento cultural sobre as modalidades esportivas.

Outra possibilidade para essa incongruência é que se evidencia ainda uma dificuldadeem avançar de forma mais consistente em conteúdos de aula que superem os conteúdos oriundos da perspectiva tradicional da pedagogia do esporte, que se restringia ao desenvolvimento de competências e habilidades para a prática do esporte, sem preocupação alargada para a formação humana e autonomia para a convivência com o esporte em sua pluralidade de forma crítica (GALATTI et al., 2014).

Observamos avanços e desafios na fala dos professores. Contudo, apenas perceber o seu ponto de vista não garante que o esporte seja adequadamente abordado na prática pedagógica com os alunos. Assim, cabe dar voz aos alunos, perguntando-lhes o que aprendem nas aulas esportivas do PEEJ, nos permitindo comparar se a aprendizagem que os alunos apontam é coerente com as expectativas e conteúdos apontados pelos professores. Portanto, veremos os resultados obtidos com a entrevista dos alunos.

Com os alunos, realizamos uma única pergunta relacionada à aprendizagem nas aulas esportivas: $O$ que vocês aprendem nas aulas esportivas do PEEJ? Por meio de uma análise coletiva apresentaremos um quadro que sintetiza as respostas, organizadas nas categorias referentes aos três Referenciais da Pedagogia do Esporte.

Quadro 4 - Aprendizagem dos alunos

\begin{tabular}{|l|l|l|}
\hline \multicolumn{1}{|c|}{ Referencial Técnico-tático } & \multicolumn{1}{|c|}{ Referencial Socioeducativo } & \multicolumn{1}{|c|}{ Referencial Histórico-cultural } \\
\hline & Educação; & \\
Fundamentos; & Atitudes; & História das modalidades; \\
Jogar modalidades; & Mídia; & Acontecimentos; \\
Movimentos; & Respeito; & Consumismo no futebol; \\
Posicionamentos; & Comportamento em quadra; & Mídia; \\
Leitura do jogo; & Consciência de seus atos; & Torcidas organizadas. \\
Melhorar fundamentos e o jogo. & Fair play; & \\
& Honestidade. & \\
\hline Total de respostas: 27 (39,7\% do & Total de respostas: 23 (33,8\% do & Total de respostas: 18 (26,4\% do \\
total) & total) & \\
\hline
\end{tabular}

Fonte: Machado (2012, p. 140) 
Observamos que, para os alunos, a aprendizagem se dá nos três referenciais da Pedagogia do Esporte, sendo indicados inclusive mais conteúdos relacionados ao referencial socioeducativo que nos demais. Realizando uma comparação entre os objetivos apresentados pelos professores e a resposta dos alunos, percebemos relação de proximidade. Contudo, ao olharmos para os conteúdos de ensino, a relação é menor, tendo em vista que alguns professores não identificaram valores e modos de comportamento como conteúdos de ensino.

No total obtivemos 68 respostas, levando em consideração que alguns alunos responderam mais de uma vez durante a entrevista ou indicaram a aprendizagem voltada para mais de um referencial. Assim, 27 respostas sinalizaram para aprendizagens dentro do referencial técnico-tático (39,7\%), 23 para o socioeducativo (33,8\%) e 18 para o históricocultural $(26,4 \%)$.

Os dados provenientes das falas dos alunos evidenciam conteúdos associados aos três referenciais; portanto, as finalidades declaradas pelos professores se manifestam no que os alunos declaram aprender, inclusive sendo citados mais conteúdos relacionados ao referencial socioeducativo do que ao técnico-tático, como evidencia o quadro 4.

No entanto, é interessante notarmos a quantidade de vezes que conteúdos citados a cada referencial aparecem na fala dos alunos: ainda que aprendizagens relacionadas ao referencial técnico-tático e socioeducativo não sejam distantes, há ainda prevalência de aprendizagens técnico-táticas. Esse dado é coerente com os conteúdos que os professores afirmam trabalhar, em que esse referencial também prevalece.

Como apontado anteriormente, Libâneo (1994) afirma que os conteúdos são organizados pelo professor, devendo ter assimilação e aplicação na vida do aluno, portanto, principalmente em projetos sociais, devem permear os conteúdos presentes no referencial socioeducativo, porém os principais apontados pelos professores ainda são referentes ao aspecto motor. Assim, nossos dados evidenciam maior relação da aprendizagem dos alunos com os conteúdos que os professores afirmam trabalhar e não com as finalidades que os mesmos afirmam ter os projetos sociais. Portanto, é importante que a formação continuada de professores que atuam em projetos sociais se preocupe em fomentar que a prática pedagógica e os conteúdos selecionados se alinhem ao objetivo educacional que prevalece nesses ambientes de educação não formal.

Outras pesquisas indicam essa necessidade, como Mello, Ferreira Neto e Votre (2009) em uma pesquisa realizada com alunos participantes do Projeto Esporte Cidadão, em Vila Velha. A fim de verificar as práticas sociais e o discurso entre os jovens participantes, encontraram um significado atribuído pelos alunos ao aperfeiçoamento esportivo - habilidade esportiva - bem como à participação em competições e a formas de interação pessoal. Essa perspectiva vai ao encontro do que a literatura hoje apresenta - o ensino do esporte pautado nas questões motoras e nos valores humanos (BARROSO; DARIDO, 2009) -, mas defendemos neste estudo a importância de articular os três Referenciais da Pedagogia do Esporte e não apenas dois deles.

Observamos, ainda, menor referência ao referencial histórico-cultural, tanto nos conteúdos dos professores como na fala dos alunos. Diversos autores apontam para o esporte como um meio de ensinar à criança e ao adolescente questões relacionadas ao comportamento e aos valores (HIRAMA, 2008; REVERDITO; SCAGLIA, 2009; PAES; BALBINO, 2009; CASTRO; 
SOUZA, 2011), outros ainda indicam para a formação de fundamentos, técnicas, táticas (BAYER, 1994; ROSE JUNIOR, 2006; GRECO; BENDA, 2007), mas, dentro de uma literatura especializada em Pedagogia do Esporte, encontramos poucos e mais recentes estudos acerca do referencial histórico-cultural (MACHADO; GALATTI; PAES, 2011; MACHADO, 2012). Essa menor e mais recente inserção desse referencial na literatura pode indicar sua menor presença na prática pedagógica nos projetos sociais.

Embora os alunos percebam a aprendizagem em diversos âmbitos: motor, físico, social, cultural, nem todos os professores os identificam em seus conteúdos de ensino. As aulas podem até ser apresentadas a partir de referenciais, mas, provavelmente, a intenção pedagógica do professor ainda esteja voltada aos aspectos motores, possivelmente pautada por uma proposta esportivista, e os demais conteúdos são tratados apenas quando surge algum problema na aula, modelo já criticado por Galatti et al. (2014), Machado, Galatti e Paes (2014), Machado (2012), Darido e Rangel (2005).

\section{CONSIDERAÇÕES FINAIS}

O trato com o esporte nos projetos sociais é, de forma recorrente, usado como bandeira de transformação social, com forte apelo político na medida em que esporte e educação são popularmente associados. No entanto, o esporte contribuirá com o processo educacional no cenário dos projetos sociais quando for intencionalmente organizado, sistematizado e aplicado com o fim de fomentar o pleno desenvolvimento de seus participantes, e não apenas mantê-los ocupados.

O esporte, para contribuir com a educação, deve ser alvo de tratamento didáticopedagógico a fim de fomentar a cultura esportiva e de estimular a criticidade da cultura geral da comunidade que abriga sua prática. Nesse sentido, os projetos sociais, ao ofertarem o esporte como meio de cidadania, devem estruturar seu programa esportivo a fim de oferecer prática e reflexão, para formar e transformar.

O ambiente estudado, denominado PEEJ, se mostrou um cenário em potencial, podendo contribuir com as propostas educacionais apresentadas por projetos sociais. Contudo, para melhor direcionar o processo de ensino, vivência e aprendizagem as propostas dos professores precisam ser intencionalmente planejadas e articuladas.

Assim, foi proposta deste artigo evidenciar o papel relevante dos projetos sociais na educação cidadã no Brasil e salientar a importância de uma prática intencional, organizada e planejada com base em Referenciais da PE para o alcance dos objetivos na educação não formal.

Indicamos a necessidade de outros estudos nessa área a fim de que tenhamos mais subsídios teórico e práticos que possam sustentar melhor as ações educativas em um cenário de ensino tão crescente no país que são os projetos sociais.

\section{REFERÊNCIAS}

BARDIN, Lawrence. Análise de conteúdo. São Paulo: Edições 70, 2011. 
BARROSO, André Luis Ruggiero; DARIDO, Suraya Cristina. A pedagogia do esporte e as dimensões dos conteúdos: conceitual, procedimental e atitudinal. Revista da Educação Física / UEM, Maringá, v. 20, n. 2, p. 281-289, ํำ trim. 2009.

BAYER, Claude. O ensino dos jogos desportivos colectivos. Porto:Vigot, 1994.

BENTO, Jorge Olímpio. Da pedagogia do desporto. In: TANI, Go; BENTO, Jorge. Olimpio; PETERSON, Ricardo Demétrio de Souza Pedagogia do desporto. Rio de Janeiro: Guanabara Koogan, 2006. Cap. 3, p. 26-40.

BRITO, Jesús Gutiérrez. Dinámica del grupo de discusión. Madri: Centro de Investigaciones Sociológicas,2008.

CASTRO, Suélen Barboza; SOUZA, Doralice Lange. Significados de um projeto social esportivo: um estudo a partir das perspectivas de profissionais, pais, crianças e adolescentes. Movimento, Porto Alegre, v. 17, n. 4, p. 154-163, out./dez. 2011.

COAKLEY, Jay. Sport in society: issues and controversies. New York: McGraw Hill, 1998.

CUNHA, Beatriz Zacchi da. A inclusão da criança em projetos sociais de educação pelo esporte. 36f. 2007. Monografia (Conclusão de Curso em Educação Física) - Universidade Federal de Santa Catarina, Florianópolis, 2007.

DARIDO, Suraya Cristina; RANGEL, Irene. A educação física na escola implicações para a prática pedagógica. Rio de Janeiro: Guanabara Koogan, 2005.

DONAHUE, Eric; RIP, Blanka; VALLERAND, Robert. When winning is everything: on passion, identity, and aggression in sport. Psychology of Sport and Exercise, Melbourne, v. 10, p. 526$534,2009$.

EIRAS, Suélen Barboza et al. Objetivos da oferta e da procura de projetos sócio-esportivos. Licere, Belo Horizonte, v. 13, n. 3, 24 p., set. 2010.

GALATTI, Larissa Rafaela. Pedagogia do esporte: o livro didático como mediador no processo de ensino e aprendizagem dos jogos esportivos coletivos, 141f. 2006. Dissertação (Mestrado em Educação Física) - Faculdade de Educação Física, Universidade Estadual de Campinas, Campinas, 2006.

GALATTI, Larissa Rafaela. Pedagogia do esporte: esporte e clube sócio-esportivo: percurso, contextos e perspectivas a partir de estudo de caso em clube esportivo espanhol. 2010. Tese (Doutorado em Educação Física) - Faculdade de Educação Física, Universidade Estadual de Campinas, Campinas, 2010.

GALATTI, Larissa Rafaela et. al. Pedagogia do esporte: procedimentos pedagógicos aplicados aos jogos esportivos coletivos. Revista Conexões, Campinas, v. 6, n. especial, p. 404-415, 2008.

GALATTI, Larissa Rafela et al. Pedagogia do esporte: tensão na ciência e o ensino dos jogos esportivos coletivos. Revista da Educação Física/UEM, Maringá, v. 25, n. 1, p. 153-162, 2014.

GALATTI, Larissa Rafaela; PAES, Roberto Rodrigues; DARIDO, Suraya Cristina. Pedagogia do esporte: livro didático aplicado aos jogos esportivos coletivos. Motriz, Rio Claro, v. 16, p. 751$761,2010$.

GIOGIO, Michael. More than a game: harnessing the power of sport to transform the lives of disadvantaged young people. [s.l.]: The Centre for Social Justice, 2011. 
GIULIANNOTTI, Richard. O setor de esporte para o desenvolvimento e a paz: um modelo sociológico de agências pacificadoras. Pensar a Prática, Goiânia, v. 15, n. 3, p. 551-820, 2012.

GRECO, Pablo Ruan; BENDA, Rodolfo Novellino. Iniciação esportiva universal 1: da aprendizagem motora ao treinamento técnico. Belo Horizonte, Ed. UFMG, 2007.

GUTIÉRREZ SANMARTÍN, Martin. Manual sobre valores en educación física y el deporte. Barcelona: Paidós, 2003.

HIRAMA, Leopoldo Katsuki. Algo para além de tirar as crianças da rua: a pedagogia do esporte em projetos socioeducativos. 356f. 2008. Dissertação (Mestrado em Educação Física) Faculdade de Educação Física, Universidade Estadual de Campinas, Campinas, 2008.

HIRAMA, Leopoldo Katsuki; JOAQUIM, Cássia dos Santos; MONTAGNER, Paulo César. Pedagogia do Esporte e estimulação de valores humanos: relato de intervenção. In: MONTAGNER, Paulo César. (Org.). Intervenções pedagógicas no esporte: práticas e experiências. São Paulo: Phorte, 2011. Cap. 6, p. 171 - 199.

HOLT, Nicholas; NEELY, Kacey. Positive youth development through sport: a review. Revista de Iberoamericana de Psicología del Ejercicio y el Deporte, Las Palmas de Gran Canaria, v. 6, n. 2, p. 299-316, 2011.

INSTITUTO BRASILEIRO DE GEOGRAFIA E ESTATÍSTICA. Censo 2010. Disponível: <http:// www.ibge.gov.br/home/estatistica/populacao/cens02010/tabelas pdf/Brasil tab_1_12.pdf>. Acesso em: 17 mar. 2014

ISAYAMA, Hélder Ferreira; LINHALES, Meily Aassbú (Org.). Avaliação de políticas e políticas de avaliação: questões para o esporte e o lazer. Belo Horizonte: Editora UFMG, 2008.

LIBÂNEO, José Carlos. Didática. São Paulo: Cortêz, 1994.

MACHADO, Gisele Viola. Pedagogia do Esporte: organização, sistematização, aplicação e avaliação de conteúdos esportivos na educação não formal. 134 f. 2012. Dissertação (Mestrado em Educação Física) - Faculdade de Educação Física, Universidade Estadual de Campinas, Campinas, 2012.

MACHADO, Gisele Viola; GALATTI, Larissa Rafaela; PAES, Roberto Rodrigues. Seleção de conteúdos e procedimentos pedagógicos para o ensino do esporte em projetos sociais: reflexões a partir dos jogos esportivos coletivos. Motrivivência, Florianópolis, v. 24, n. 39, p. 164-176, dez. 2011.

MACHADO, Gisele Viola; GALATTI, Larissa Rafaela; PAES, Roberto Rodrigues. Pedagogia do Esporte e o Referencial Histórico-cultural: interlocução entre teoria e prática. Pensar a Prática, Goiânia, v. 17, n. 2, p. 414-430, jan./mar. 2014.

MARCONI, Marina de Andrade; LAKATOS, Eva Maria. Fundamentos de metodologia científica. 7. ed. São Paulo: Atlas, 2010.

MARTINS, Carlos Henrique dos Santos; MELO, Marcelo de Paula. Políticas públicas de esportes para a juventude na baixada fluminense/ RJ: uma discussão introdutória. In: ANPED, 27., 2003, Caxambu. Anais... Caxambu, 2003. Disponível em: <http://27reuniao.anped.org.br/ gt03/t034.pdf>. Acesso em: 5 jan. 2014.

MELLO, André da Silva; FERREIRA NETO, Amarílio; VOTRE, Sebastião Josué. Intervenção 
da Educação Física em projetos sociais: uma experiência de cidadania e esporte em Vila Velha (ES). Revista Brasileira de Ciências do Esporte, Campinas, v. 31, n. 1, p. 75-91, set. 2009.

MELO, Marcelo de Paula. Lazer, Esporte e Cidadania: debatendo a nova moda do momento. Movimento, Porto Alegre, v. 10, n. 2, p. 105-122, maio/ago. 2004.

PAES, Roberto Rodrigues. Educação Física Escolar: o Esporte como conteúdo pedagógico no Ensino Fundamental, 1996. 206f. Tese (Doutorado em Educação Física) - Faculdade de Educação Física, Universidade Estadual de Campinas, Campinas, 1996.

PAES, Roberto Rodrigues; BALBINO, Hermes Ferreira. A pedagogia do esporte e os jogos coletivos. In: ROSE JUNIOR, Dante de et al. Esporte na infância e adolescência: uma abordagem multidisciplinar. 2. ed. Porto Alegre: Artmed. 2009. Cap. 5, p. 73-83.

PROGRAMA ENSINO ESPORTE E JUVENTUDE: Documentos administrativos. Taubaté: Prefeitura Municipal de Taubaté, 2008.

PROGRAMA ENSINO ESPORTE E JUVENTUDE: Planejamento esportivo. Taubaté: Prefeitura Municipal de Taubaté, 2011.

REVERDITO, Riller da Silva; SCAGLIA, Alcides José. Pedagogia do esporte: jogos coletivos de invasão. São Paulo: Phorte, 2009.

ROSE JUNIOR, Dante de. Modalidades esportivas coletivas. Rio de Janeiro: Guanabara Koogan, 2006.

SCHULENKORF, Nico. The roles and responsibilities of a change agent in sport event development projects. Sport Management Review, Melbourne, v. 13, p. 118-128, 2010.

SOUZA, Doralice Lange et al. Determinantes para a implementação de um projeto social. Motriz, Rio Claro, v. 16, n. 3, p. 689-700, jul./set. 2010.

ZABALA, Antoni. A prática educativa. Porto Alegre: Artmed, 1998.

ZALUAR, Alba. Cidadãos não vão ao paraíso. Campinas, SP: Escuta, 1994. 